\title{
The measurement of surface roughness to determine the suitability of different methods for stone cleaning
}

\author{
Carmen Vazquez-Calvo, Monica Alvarez de Buergo, Rafael Fort \\ and Maria Jose Varas-Muriel \\ Instituto de Geociencias IGEO (CSIC-UCM), Jose Antonio Novais 2, 28040 Madrid, Spain \\ E-mail: alvarezm@geo.ucm.es and monica.alvarez@csic.es
}

Received 26 January 2012

Accepted for publication 8 June 2012

Published 9 August 2012

Online at stacks.iop.org/JGE/9/S108

\begin{abstract}
The roughness of stone surface was measured, before and after bead blasting-based cleaning methods, to select the most efficient one to be used in masonry and stonework of specific areas of the Cathedral of Segovia (Spain). These types of cleaning methods can, besides the removal of soiling and surface deposits, leave a rougher surface, which would mean higher and more rapid water retention and deposit accumulation due to a specific surface increase, therefore accelerating stone decay. Or, in contrast, the cleaning method can be so aggressive that it can smooth the surface by reducing its roughness, a fact that usually corresponds to excessive material removal - soot and deposits - but also part of the stone substrate. Roughness results were complemented with scanning electron microscopy observations and analyses and colour measurements. Finally, it was possible to select the best cleaning method among the six that were analysed, for different areas and different stone materials. Therefore, this study confirms the measurement of surface roughness as a reliable test to determine the suitability of stone cleaning methods; it is a non-destructive technique, portable and friendly to use, which can help us to rapidly assess - together with other techniques - the efficacy and aggressiveness of the stone cleaning method.
\end{abstract}

Keywords: surface properties, stone conservation, roughness, cleaning

\section{Introduction, background and aims}

The scientific contribution to heritage conservation must be to assess the efficacy and suitability of any method in the laboratory and in situ before its application in the artwork, monument or building, as in the case of any stone cleaning method.

The assessment of stone cleaning methods can comprise many tests, analyses, techniques and property determination studies.

Here we present a procedure combining the determination of roughness, together with colour measurements and the observation and analysis by SEM-EDS, before and after cleaning. The former two are determined by the use of non-destructive and portable techniques; regarding the latter, very small samples are needed and significant information is obtained from each of them.

Materials roughness is a physical characteristic of the surface texture that can deeply affect their durability due to its influence on particle retention and adhesion capacity, which may cause their further decay, e.g. organic matter particles, water drops and/or atmospheric pollution particles that can lead to soiling and salt crystallization processes (black crusts). In general, an increase in materials roughness also increases the specific surface and therefore, the material is more exposed to all environmental agents.

Roughness can be qualitatively or quantitatively assessed by means of different techniques at different scales: optical microscopy, scanning electron microscopy, confocal microscopy, atomic force microscopy, stylus profilometry, laser triangulation profilometry, reflected-light image analysis, 
white light interferometry, optical profilometry, digital holography, etc. Among all of them, optical profilometry is a contact-free technique that consists of the projection of a grid of lines onto the surface at a certain angle, making evident any irregularity in the surface.

In the case of stone decay and stone conservation, surface roughness has been measured to assess different processes, such as ageing, weathering or deterioration (Jaynes and Cooke 1987, Guidobaldi and Mecchi 1993, Benavente et al 2003, Lopez-Arce et al 2010b), consolidation efficacy (Lopez-Arce et al 2010a), hydrophobization (Manoudis et al 2007, 2009, Della Volpe et al 2000, Illescas and Mosquera 2011) and also the suitability of stone cleaning methods (Young et al 1994, Grissom et al 2000, Colombo et al 2007, Alvarez de Buergo et al 2011). Moreover, even stone sculpture authorships have been analysed recently (Fort et al 2012), by measuring the marks left on the stone surface by tools and engraving techniques.

This study was performed at the end of 2009 and the beginning of 2010, as part of the studies and analysis prior to the restoration project of the cloister of the cathedral of Segovia, Spain. The efficacy and non-aggressiveness of the stone cleaning methods previously determined in the projectblasting-based methods (Iglesias et al 2006) —was the main aim of this study, in order to apply the most adequate conditions to avoid any further stone decay.

First references to roughness meters, to measure the materials surface texture, go back to 1930, when 2D contact profilometers were being used. Nowadays there are optical or laser roughness meters that allow us to obtain 3D maps (topography) of the materials surface. Standard ISO 4287:1984 defines roughness parameters as follows: $\mathrm{Ra}$ is the arithmetic mean of the absolute values of the deviations from the profile average; $\mathrm{Rq}$ is the deviation from the square root of the measurement profile total; and $\mathrm{Rz}$ is the sum of the vertical distances of the five highest (peaks) and the five deepest (valleys) values of each measurement.

Roughness measurements in heritage stone materials are very useful to assess the efficacy and the aggressiveness of cleaning methods, or to measure how consolidation products applied to these materials modify the surface roughness. The less any treatment varies the surface roughness, the better, as when the characteristics of a material surface change, the material needs to adapt to the new conditions, meaning alteration.

The aim of this work is to assess the suitability and efficiency of a series of blasting-based stone cleaning methods, with the aid of the combination of the variation of the stone surface measurements, together with colour measurements and SEM observations.

\section{Materials and methods}

\section{Materials}

The stone materials correspond to the stone masonry of the Cathedral of Segovia, Spain, and the area to be cleaned, i.e. the cloister. The main building stones are dolomitic limestonedolomitized oobioesparite according to Folk (1962), or dolomitized packstone of oolites and bioclasts according to Dunham (1962) - (white variety, $W$ ), with dolomite, calcite and clay minerals as the main minerals; and a dolostonemicro and meso-crystalline dolostone (yellow variety, Y), mainly composed of dolomite, calcite, quartz, hematite and clay minerals.

\section{Methods}

Petrographic and mineralogical analysis. The petrographic analysis of the stone materials and the surface deposits on them was performed with the aid of an Olympus BX51 polarized optical microscope fitted with an Olympus DP12 digital camera. The carbonate rocks were partially stained with alizarin red to distinguish calcite from dolomite. Crosssections of the stone samples were observed, analysing the surface deposits to be removed by cleaning. Mineralogical analyses of the powder fraction from the entire sample were performed by means of an x-ray diffractometer (Philips Analytical PW 1752), operated at $40 \mathrm{kV}$ and $30 \mathrm{~mA}$, equipped with a copper K-alpha anode tube, graphite monochromator and PC-ADP diffraction software. Measurements were taken in the $2^{\circ}-65^{\circ}$ range at a step size of $0.02^{\circ}$, and $2^{\circ} \mathrm{min}^{-1}$ in continuous mode.

A JEOL JSM 6400 scanning electron microscope was also used, with an EDS x-ray OXFORD-LINK PENTAFET microanalyzer. Samples were analysed both as fragments and as thin sections, graphite sputtered to make them electron conductive. Both surface (fragments) and cross-sections (polished thin sections) were analysed. Analyses were performed before and after cleaning trials.

Colour analysis. A MINOLTA CM-700d spectrophotometer was used to measure CIELab (Commission Internationale de l'Eclairage, CIE 1976) colour parameters $\left(L^{*}, a^{*}\right.$ and $\left.b^{*}\right)$ under a D65 light source. $L^{*}$ denotes lightness, $a^{*}$ is the red-green scale indicator (the more positive the value, the redder the specimen and the more negative, the greener), and $b^{*}$ the blue-yellow scale indicator (the more positive the value, the yellower the specimen and the more negative, the bluer).

Colour parameters have been previously determined by some of the co-authors for stone cleaning assessment purposes (Fort et al 2000, Perez-Monserrat et al 2011).

Roughness measurements. Roughness was measured with a TRACEit optical surface (OSR) roughness tester. This portable, white light analyser takes roughness measurements non-destructively and produces 3D topographic maps showing roughness on a micro-scale (microns). The measuring field was $5 \mathrm{~mm} \times 5 \mathrm{~mm}$ and the resolution along both the $Z$ and the $X / Y$-axes was $2.5 \mu \mathrm{m}$. The mean values for the roughness parameters, $\mathrm{Ra}, \mathrm{Rq}$ and $\mathrm{Rz}$, were obtained from the $25 \mathrm{~mm}^{2} 3 \mathrm{D}$ micro-topographic maps. Among these parameters, $\mathrm{Rz}$ was selected as the best one to compare before and after cleaning. 

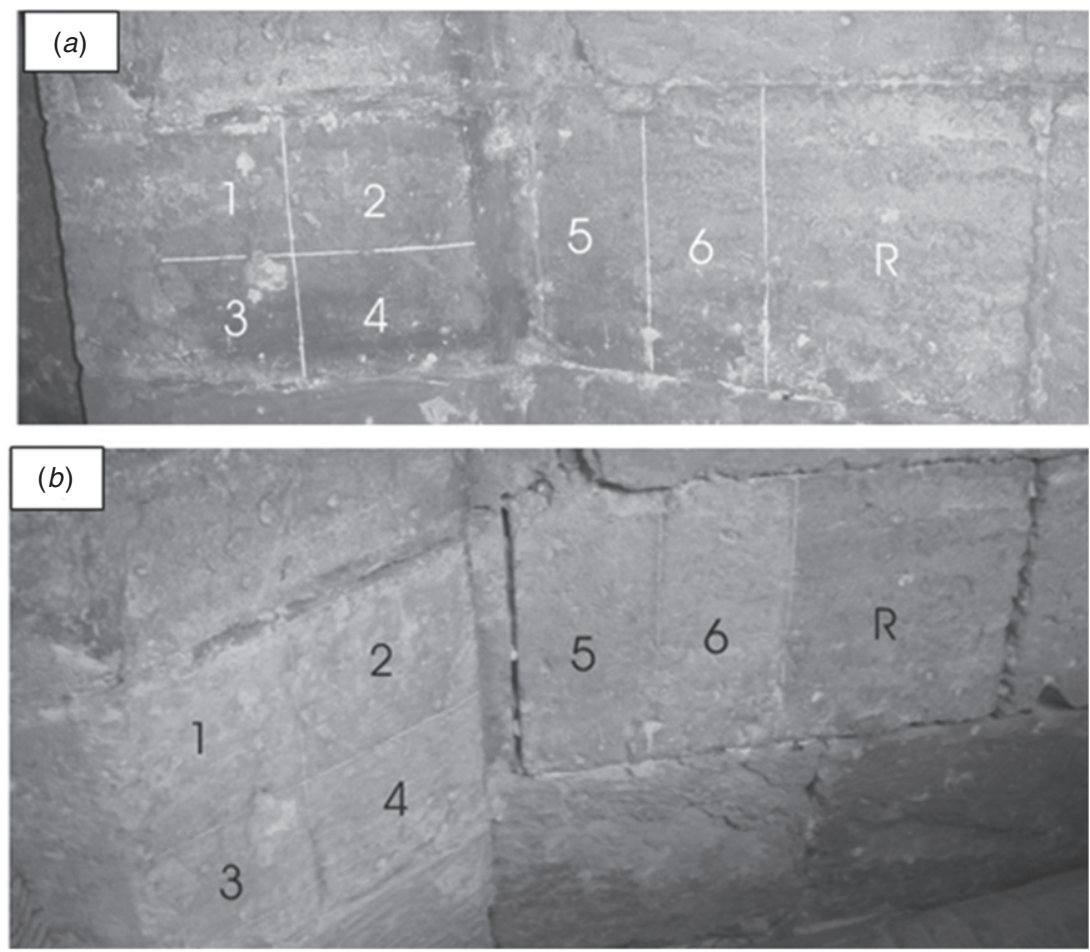

Figure 1. (a) Selected area of white stone variety to be cleaned, and $(b)$ the same area after cleaning trials. $\mathrm{R}$ is the reference testing area, which remained uncleaned for comparison purposes, and 1 to 6 are the testing areas in which the six cleaning operating conditions were applied.

Table 1. Particle nature and size, and cleaning pressure of the different stone cleaning methods.

\begin{tabular}{llll}
\hline $\begin{array}{l}\text { Operating } \\
\text { conditions }\end{array}$ & $\begin{array}{l}\text { Particle } \\
\text { nature }\end{array}$ & $\begin{array}{l}\text { Particle } \\
\text { size }\end{array}$ & Pressure \\
\hline 1 & Glass micro-spheres & $90 / 150 \mu \mathrm{m}$ & $<1 \mathrm{~atm}$ \\
2 & Glass micro-spheres & $90 / 150 \mu \mathrm{m}$ & $>1<3 \mathrm{~atm}$ \\
3 & Aluminium oxide 150 & $105 \mu \mathrm{m}$ & $<1 \mathrm{~atm}$ \\
4 & Aluminium oxide 150 & $105 \mu \mathrm{m}$ & $>1<3 \mathrm{~atm}$ \\
5 & Aluminium oxide 180 & $88 \mu \mathrm{m}$ & $<1 \mathrm{~atm}$ \\
6 & Aluminium oxide 180 & $88 \mu \mathrm{m}$ & $>1<3 \mathrm{~atm}$ \\
\hline
\end{tabular}

Assessment of cleaning method. Different particle nature, particle size and pressure were tested, resulting in six different operating conditions (table 1). All particles were round-shaped (spheres).

Cleaning tests were performed in the area to be cleaned (the cloister of the Cathedral) in both the white and yellow stone varieties. For this purpose, in each testing area, a net of seven squares/rectangles were drawn with lime to be analysed before and after cleaning them with each of the six different operating conditions, plus one area of reference that remained uncleaned for comparison purposes (figures 1 and 2).

Prior to the cleaning process, small samples from the stone substrate were petrographically studied, and the nature and thickness of the soiling or surface deposits determined, by polarizing optical and scanning electron microscopy.

Colour and roughness were measured before and after the cleaning trials.

Regarding colour, the purpose was to determine the operating conditions with which the total difference of colour, according to CIELab $1976\left(\Delta E^{*}=\left[\left(\mathrm{d} L^{*}\right)^{2}+\left(\mathrm{d} a^{*}\right)^{2}+\left(\mathrm{d} b^{*}\right)^{2}\right]^{\frac{1}{2}}\right)$, calculated from the cleaned testing areas with respect to the same uncleaned areas, was the greatest. The higher the $\Delta E^{*}$, the more effective the stone cleaning method, considering the method removes the surface deposits on the stone.

With respect to roughness measurements, the most efficient cleaning method should be one that removes the most surface deposits (or reduces the thickness of such surface deposits to the minimum), with minimum modification of the surface roughness. But it is likely that by increasing the stone surface roughness (which would result on increasing the specific surface of the stone and therefore accelerating its decay) and diminishing it too much so as to flatten it, in addition to the removing the surface deposits, can go deep into the stone, removing part of it as well.

Three measurements were performed in each testing rectangular area, considering two values of $\mathrm{Rz}$, along both the $X$ and $Y$ axes, and calculating the average and standard deviation as the final value. 3D roughness maps were also obtained.

\section{Results}

Petrographical and mineralogical analyses of the stone varieties

The 'white variety' is massive, hard and compact. It is in general white coloured, with some reddish areas linked to fissures and to the concentration of iron-rich compounds ('terra rosa'). It is a dolomitized oobiosparite according to Folk (1962), or a dolomitized packstone of oolites and bioclasts 

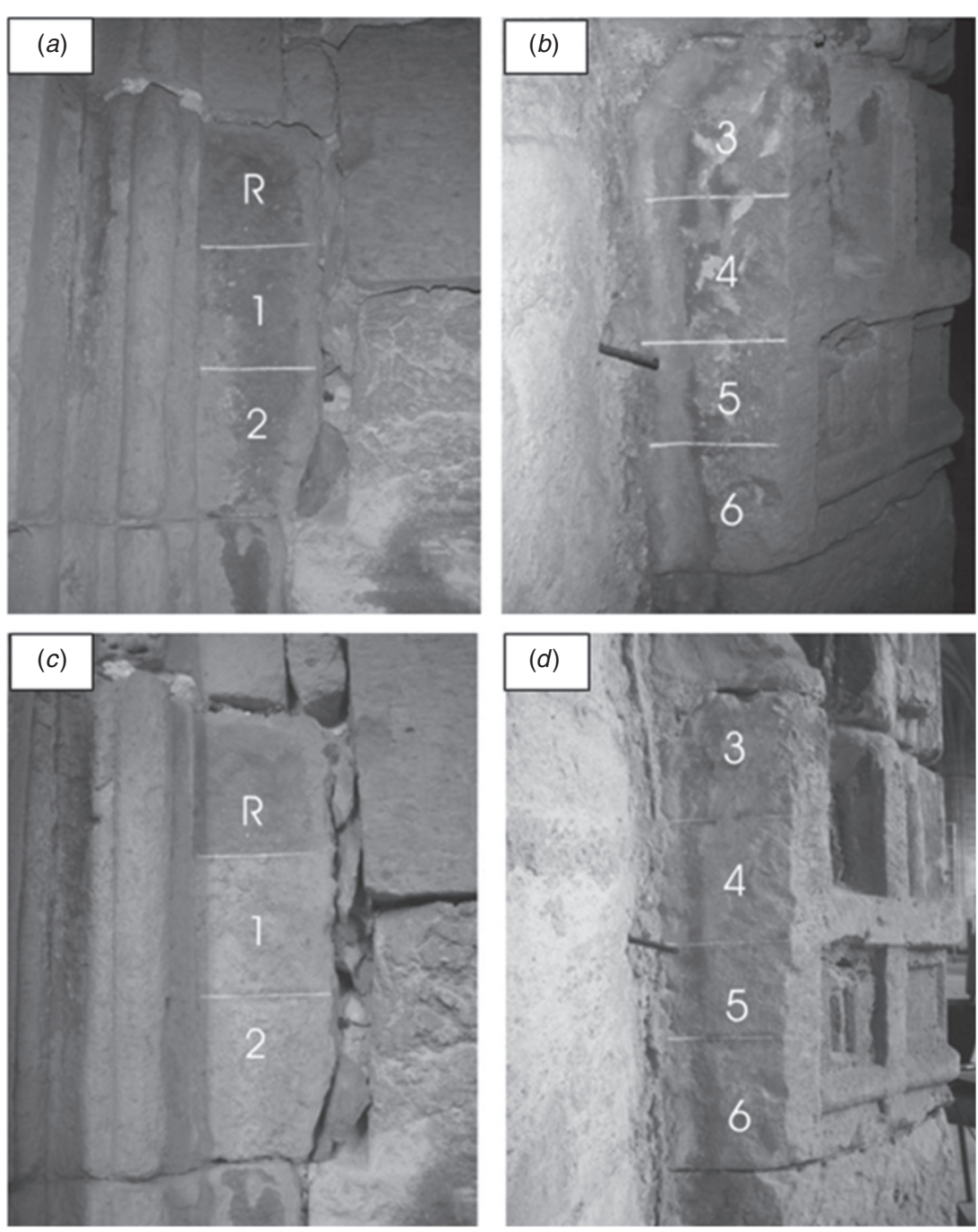

Figure 2. Plots $(a)$ and $(b)$ correspond to the selected area of yellow stone variety to be cleaned. Plots $(c)$ and $(d)$ are the same area after cleaning trials. $\mathrm{R}$ is the reference testing area, which remained uncleaned for comparison purposes, and 1 to 6 are the testing areas in which the six cleaning operating conditions were applied.

according to Dunham (1962). It has a high content of bioclasts $(20-30 \%)$, most of them are fragments of mainly gastropods and bivalves. These bioclasts are dispersed and usually range from 1 to $6 \mathrm{~mm}$ size, with their edges frequently micritized. Their inner structure is cemented by sparite crystals (calcite, with large crystals sometimes higher than $500 \mu \mathrm{m}$ ), and they are included in a micrite matrix (cryptocrystalline dolomite), and slightly porous (intercrystalline porosity, pore size $<2 \mathrm{~mm}$ ). Micrite is sometimes concentrated in spherical and ellipsoidal nodules $(500-750 \mu \mathrm{m})$, which really account for oolites that have been micritized with significant dissolution processes (that is the reason for the micrite edges). Porosity of this white variety is very high (25-30\%), and mainly a mouldic porosity (intra- and intergranular).

XRD analyses revealed dolomite and calcite as the main minerals, with traces of clay minerals (muscovite/illite) and alteration products (gypsum, epsomite, hydromagnesite and wavellite).

The 'yellow variety' corresponds to a very fine grainsize (micro-mesocrystalline, ranging from 30 to $100 \mu \mathrm{m}$ ) dolostone, composed of rhombic and equigranular crystals, with dark and dirty crystal nuclei accounting for the dolomite alteration by dissolution, a typical alteration that occurs when the percentage of micro-pores is high.

Total porosity observed in thin section under the polarizing optical microscope was estimated from $1 \%$ to $5 \%$; it is an inter-crystalline porosity, irregular shaped pores, and usually with a pore diameter smaller than $500 \mu \mathrm{m}$. In some samples of this type of dolostone, sparry carbonate cement (sparite) can be observed (in a percentage ranging from $1 \%$ to $5 \%$ ). Also some dispersed quartz grains can be found in this rock (up to 5\%), monocrystalline and subangular shaped, with highly corroded rims, and a grain size from around 30 to $60 \mu \mathrm{m}$.

The iron gel content is responsible for the yellowishreddish colour of this stone variety. The iron-rich compounds are heterogeneously distributed around the rock, surrounding dolomite crystals or concentrating in some points/areas. There are some clay minerals linked to the presence of these iron gels.

Mineralogically, XRD results show the presence of dolomite as the main mineral, and quartz and hematite as secondary ones. Other minerals found in this dolostone $(<5 \%)$ 

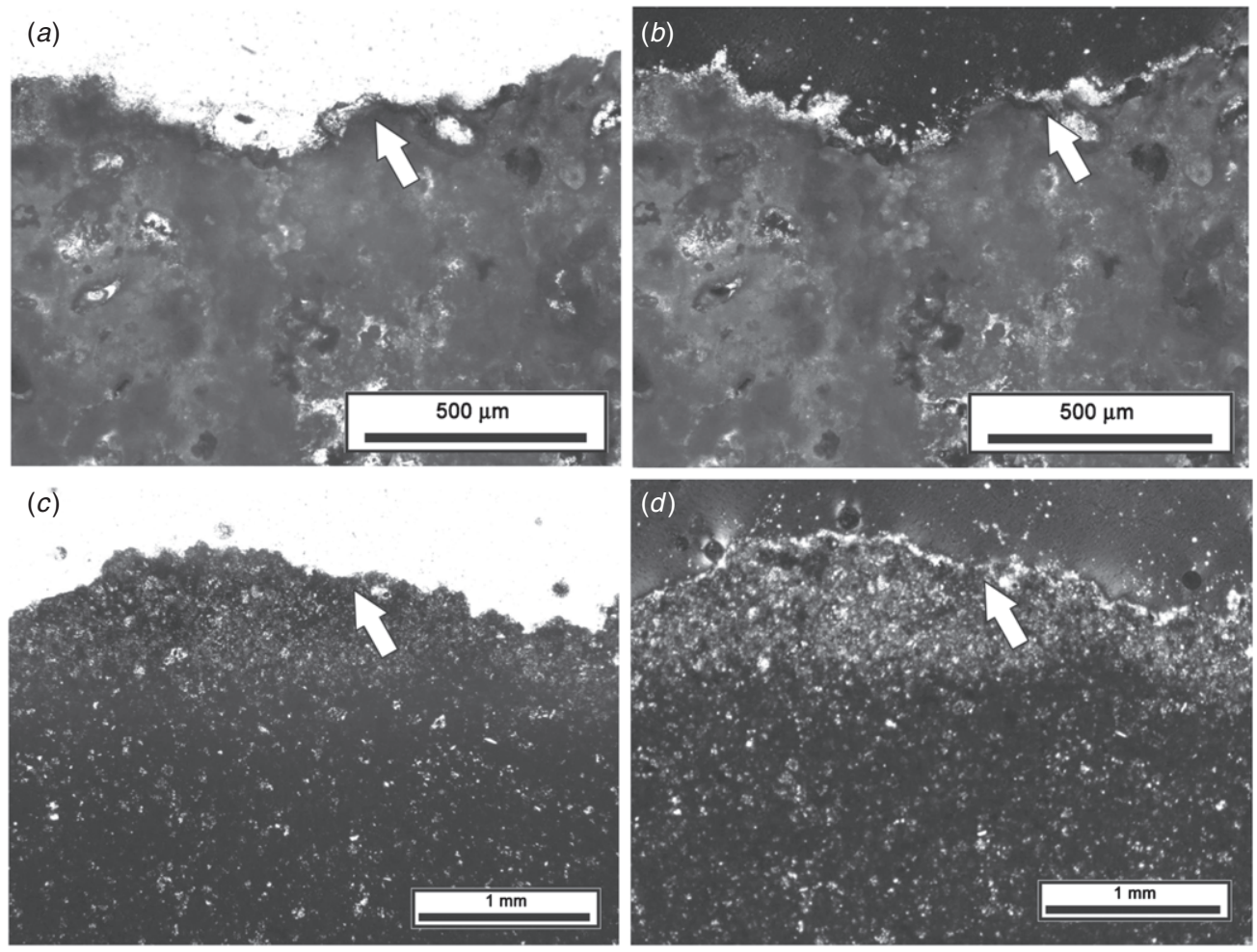

Figure 3. Polarizing optical microscopy images of stone cross sections with the surface deposits (white arrows) on top of the stone surfaces. Plots $(a)$ and $(b)$ white variety stone, natural and polarized light, respectively; $(c)$ and $(d)$ yellow variety stone, natural and polarized light, respectively.

are micas (muscovite and illite), clay minerals (smectite, palygorskite and kaolinite) and some salts as a result of decay processes to which the building is subjected (gypsum, hexahydrite, rozenite, wavellite and hydromagnesite).

\section{Analysis of the deposits on the stone surface before cleaning}

Figure 3 shows the appearance under a polarizing optical microscope of both the stone substrates and the surface deposits on them, of both cross sections of the white (figures 3(a) and (b)) and yellow varieties (figures 3(c) and $(d)$ ). From these images a higher continuity of the surface deposits on the yellow stone with respect to the white one can be observed, besides the fact that in both cases this soiling is not very thick (of micrometric scale) as well as that the initial roughness of the white stone is slightly higher than of the yellow one.

Scanning electron microscopy (SEM) used for the study of these samples (figure 4), showed, on the white stone variety, a thin cover of surface deposits with a composition similar to that of clay minerals and the presence of fungi filaments. Also gypsum crystals and, in some areas, small particles of titanium oxides were detected. Moulds of different fossils can be observed in the white stone in polished thin cross sections, and organic matter was identified in the surface deposits, sometimes surrounded by gypsum crystals. These deposits do not cover the stone in a continuous way, being approximately $70 \mu \mathrm{m}$ thick (figures $4(a)-(d)$ ). The more frequent presence of organic matter in this variety could be favoured by the fact that the testing areas were closer to the ground level (around $50 \mathrm{~cm}$ above it), while the testing areas of the yellow stone variety was higher, i.e. $140 \mathrm{~cm}$ above cloister floor level. On the yellow stone variety (figures $4(e)-(h)$ ), a substrate composed of calcite and dolomite was observed by SEM, together with the presence of clay minerals, spores and two types of particles: one type is round-shaped, rich in $\mathrm{Si}$ and $\mathrm{Al}$, and some K (EDS analyses); their presence could be accounted for by a previous cleaning event using alumina, or as a result of atmospheric pollution (spheres of $20 \mu \mathrm{m}$ in diameter). The second type is constituted by particles mainly composed by $\mathrm{Na}$ and $\mathrm{O}$ that could be the residues of a cleaning process in which soda was used. Quartz, gypsum and dolomite were also observed. Dolomite probably corresponds to the stone substrate, as could also happen for quartz. Estimated thickness of the surface deposits is around $50 \mu \mathrm{m}$.

\section{Roughness measurements}

Table 2 shows the results for the Rz parameter before the cleaning trials, and table 3 after them. A total of 2000 data were collected. Table 4 summarizes the variation, in absolute values, of $\mathrm{Rz}$ before and after the cleaning tests. The results show that operating conditions of the cleaning methods 1 and 3 resulted in less variation of roughness for the white stone variety, and 3 and 4 for the yellow stone variety, considering the threshold in five units. From these results, it is cleaning method \#3 (aluminium oxide 150, $105 \mu \mathrm{m}$, $<1$ atm) which is the most adequate cleaning method considering the roughness measurements. 

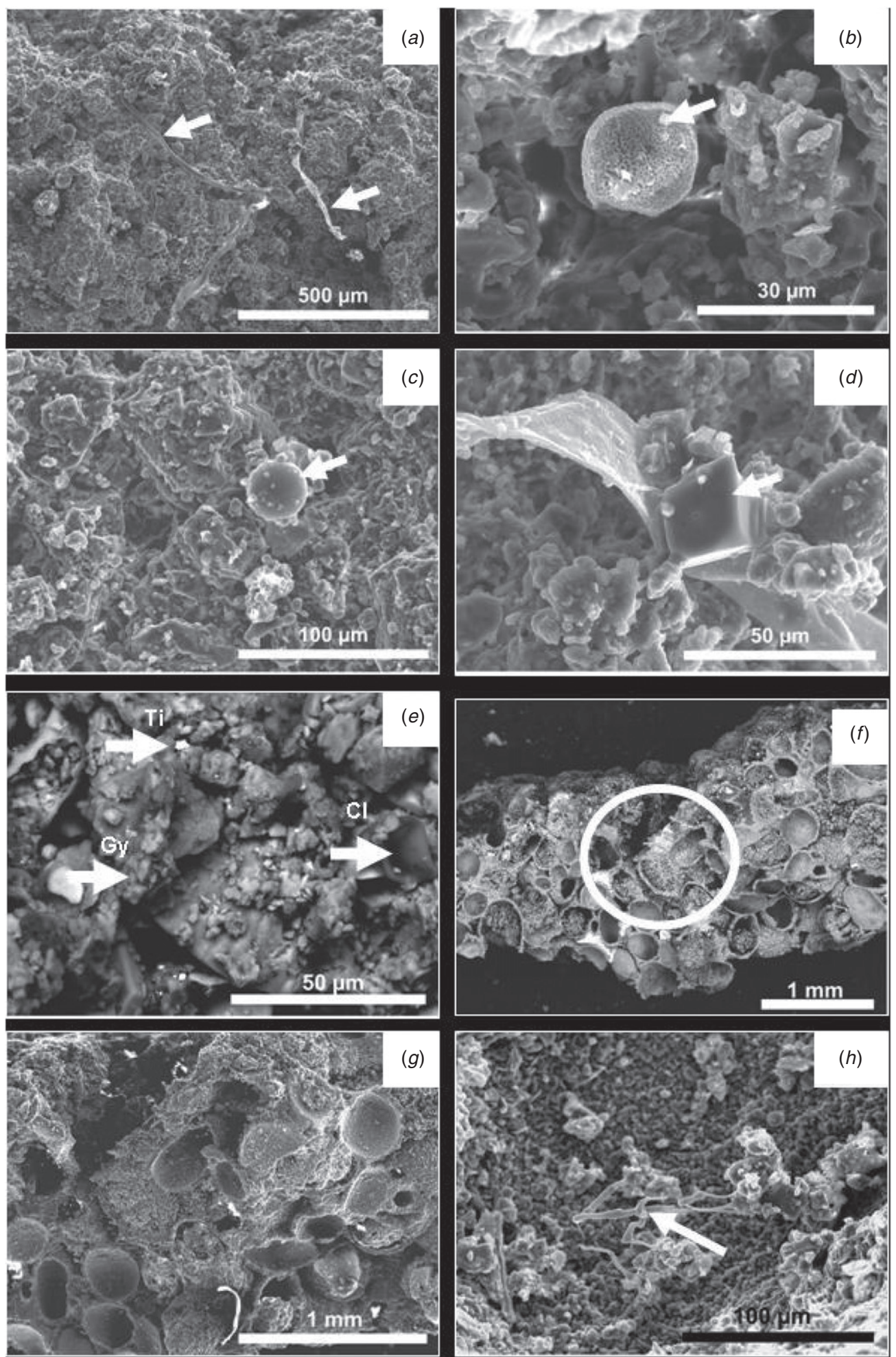

Figure 4. SEM images of stone substrates $((a)-(d)$, white stone variety; $(e)-(h)$, yellow stone variety), and surface deposits on them.

(a) Detail of clays (white arrows) on the stone; $(b)$ the arrow points to a pollen particle; $(c)$ the arrow points to a spherical particle composed of $\mathrm{Si}, \mathrm{Al}, \mathrm{K}$ and $\mathrm{Fe} ;(d)$ rhomboid particle on a clay plate composed of $\mathrm{Na}$ and $\mathrm{O} ;(e)$ gypsum crystals (Gy) on the stone surface, as well as clay minerals $(\mathrm{Cl})$ and Ti oxide particles $(\mathrm{Ti}) ;(f)$ a stone fragment with its external surface on the top; $(g)$ detail of image $(f)$, in which surface deposits or soiling can be observed on the top, with a composition of $\mathrm{Ca}$ and $\mathrm{Mg}$ (substrate) and $\mathrm{Si}$ and $\mathrm{Al} ;(h)$ the arrow points to a fungus filament on the stone surface.

Figure 5 shows 3D roughness maps obtained on the stone testing areas, before and after the cleaning trials. The four graphics on the top of the figure represent the change in rugosity of the cleaning method \#3, which did not change significantly the initial roughness of the surface of both stone varieties, white and yellow. In contrast, the last four graphics at the bottom of the figure represent the results of using two cleaning methods (\#5 for the white stone: W5 and \#1 for the 
Table 2. Rz values (in $\mu \mathrm{m}$ ) obtained before the cleaning tests, along $X$ and $Y$ axes, in both yellow and white stone varieties.

\begin{tabular}{lll}
\hline Trial areas before cleaning & $X$-axis & $Y$-axis \\
\hline White 1 & $44 \pm 3$ & $46 \pm 10$ \\
White 2 & $29 \pm 5$ & $30 \pm 5$ \\
White 3 & $30 \pm 7$ & $35 \pm 11$ \\
White 4 & $27 \pm 6$ & $32 \pm 16$ \\
White 5 & $25 \pm 11$ & $24 \pm 8$ \\
White 6 & $36 \pm 13$ & $31 \pm 9$ \\
Yellow 1 & $17 \pm 11$ & $21 \pm 15$ \\
Yellow 2 & $14 \pm 9$ & $19 \pm 17$ \\
Yellow 3 & $26 \pm 6$ & $26 \pm 7$ \\
Yellow 4 & $24 \pm 15$ & $26 \pm 15$ \\
Yellow 5 & $33 \pm 13$ & $39 \pm 20$ \\
Yellow 6 & $28 \pm 11$ & $34 \pm 14$ \\
\hline
\end{tabular}

Table 3. Rz values (in $\mu \mathrm{m}$ ) obtained after the cleaning tests, along $X$ and $Y$ axes, in both white and the yellow stone varieties.

\begin{tabular}{lll}
\hline Trial areas after cleaning & $X$-axis & $Y$-axis \\
\hline White 1 & $45 \pm 4$ & $50 \pm 5$ \\
White 2 & $45 \pm 11$ & $48 \pm 13$ \\
White 3 & $34 \pm 5$ & $38 \pm 7$ \\
White 4 & $37 \pm 13$ & $39 \pm 16$ \\
White 5 & $47 \pm 5$ & $50 \pm 6$ \\
White 6 & $20 \pm 8$ & $29 \pm 14$ \\
Yellow 1 & $32 \pm 4$ & $31 \pm 1$ \\
Yellow 2 & $30 \pm 8$ & $26 \pm 6$ \\
Yellow 3 & $30 \pm 13$ & $30 \pm 10$ \\
Yellow 4 & $27 \pm 6$ & $27 \pm 4$ \\
Yellow 5 & $37 \pm 4$ & $32 \pm 6$ \\
Yellow 6 & $26 \pm 16$ & $22 \pm 8$ \\
\hline
\end{tabular}

Table 4. Rz value variations obtained before and after the cleaning trials in both white and the yellow stone varieties.

\begin{tabular}{lcc}
\hline $\begin{array}{l}\text { Trial } \\
\text { areas }\end{array}$ & $\begin{array}{l}\text { Rz variation } \\
\text { along } X \text { axis, } \mu \mathrm{m} \\
\text { (before/after) }\end{array}$ & $\begin{array}{l}\text { Rz variation } \\
\text { along } Y \text { axis, } \mu \mathrm{m} \\
\text { (before/after) }\end{array}$ \\
\hline White 1 & 1 & 4 \\
White 2 & 16 & 18 \\
White 3 & 5 & 3 \\
White 4 & 11 & 7 \\
White 5 & 21 & 26 \\
White 6 & -16 & -2 \\
Yellow 1 & 15 & 9 \\
Yellow 2 & 15 & 7 \\
Yellow 3 & 4 & 4 \\
Yellow 4 & 2 & 1 \\
Yellow 5 & 3 & -8 \\
Yellow 6 & -3 & -13 \\
\hline
\end{tabular}

yellow stone: Y1). The increase of roughness after using these methods can be observed in these graphics.

From all the results it can be inferred that in general, roughness after cleaning increases more in the white stone variety than in the yellow one.

\section{Colour measurements}

In table 5 the values of colour measurements on the stone testing areas-both in the white and yellow varieties-before
Table 5. Chromatic parameters obtained in the stone trial areas before cleaning tests.

\begin{tabular}{lllll}
\hline $\begin{array}{l}\text { Trial areas } \\
\text { before cleaning }\end{array}$ & $L^{*}$ & $a^{*}$ & $b^{*}$ & $C^{*}$ \\
\hline White 1 & $61 \pm 2$ & $2.9 \pm 0.1$ & $14 \pm 1$ & $15 \pm 1$ \\
White 2 & $59 \pm 5$ & $2.9 \pm 0.2$ & $14 \pm 1$ & $14 \pm 1$ \\
White 3 & $52 \pm 4$ & $3.2 \pm 0.3$ & $14 \pm 1$ & $14 \pm 1$ \\
White 4 & $49 \pm 4$ & $3.1 \pm 0.2$ & $13 \pm 1$ & $14 \pm 1$ \\
White 5 & $56 \pm 2$ & $3.4 \pm 0.1$ & $15 \pm 1$ & $15 \pm 1$ \\
White 6 & $56 \pm 3$ & $3.5 \pm 0.4$ & $15 \pm 1$ & $16 \pm 1$ \\
Yellow 1 & $52 \pm 1$ & $4.9 \pm 0.4$ & $20 \pm 1$ & $20 \pm 1$ \\
Yellow 2 & $50 \pm 3$ & $4.5 \pm 0.5$ & $18 \pm 1$ & $18 \pm 1$ \\
Yellow 3 & $48 \pm 4$ & $3.2 \pm 0.4$ & $15 \pm 1$ & $15 \pm 1$ \\
Yellow 4 & $44 \pm 3$ & $3.5 \pm 0.7$ & $15 \pm 2$ & $16 \pm 2$ \\
Yellow 5 & $46 \pm 4$ & $4.0 \pm 0.3$ & $17 \pm 2$ & $17 \pm 2$ \\
Yellow 6 & $49 \pm 4$ & $4.1 \pm 0.3$ & $18 \pm 2$ & $18 \pm 2$ \\
\hline
\end{tabular}

Table 6. Total colour change calculated on the cleaned stone testing areas with respect to the same uncleaned ones (before/after cleaning).

\begin{tabular}{lllr}
\hline Testing area & $\Delta E$ & Testing area & $\Delta E$ \\
\hline White 1 & 13 & Yellow 1 & 8 \\
White 2 & 13 & Yellow 2 & 10 \\
White 3 & 20 & Yellow 3 & 14 \\
White 4 & 21 & Yellow 4 & 12 \\
White 5 & 13 & Yellow 5 & 10 \\
White 6 & 16 & Yellow 6 & 11 \\
\hline
\end{tabular}

the cleaning trials are shown, and the total colour change $\Delta E^{*}$ calculated from measuring cleaned areas with respect to the uncleaned ones can be observed in table 6. In general terms, results show how the cleaning methods seem to be more effective for the white stone (higher $\Delta E^{*}$ ) than for the yellow.

\section{Analysis of the deposits on the stone surface after cleaning}

After the stone cleaning tests, two samples cleaned with two methods that provided good results in terms of roughness measurements were analysed under scanning electron microscopy (figure 6), both looking at the stone surface (fragment samples) (figures $6(a)$ and $(c)$ ) and to the stone cross-section (polished thin sections) (figures $6(b)$ and $(d)$ ), in both stone varieties.

In the white stone variety, remains of surface deposits/soiling can still be observed in the valleys of the stone surface, which means that the cleaning method removed most of the stone surface deposits, leaving a rougher surface (higher roughness) as observed in the yellow stone, confirmed by the roughness results above mentioned.

In the yellow stone variety, a continuous surface deposit cover is still observed. This fact confirms what was obtained by means of colour measurements, i.e. cleaning of the white stone, using the same earlier methods, was more effective in the white variety than in the yellow. 

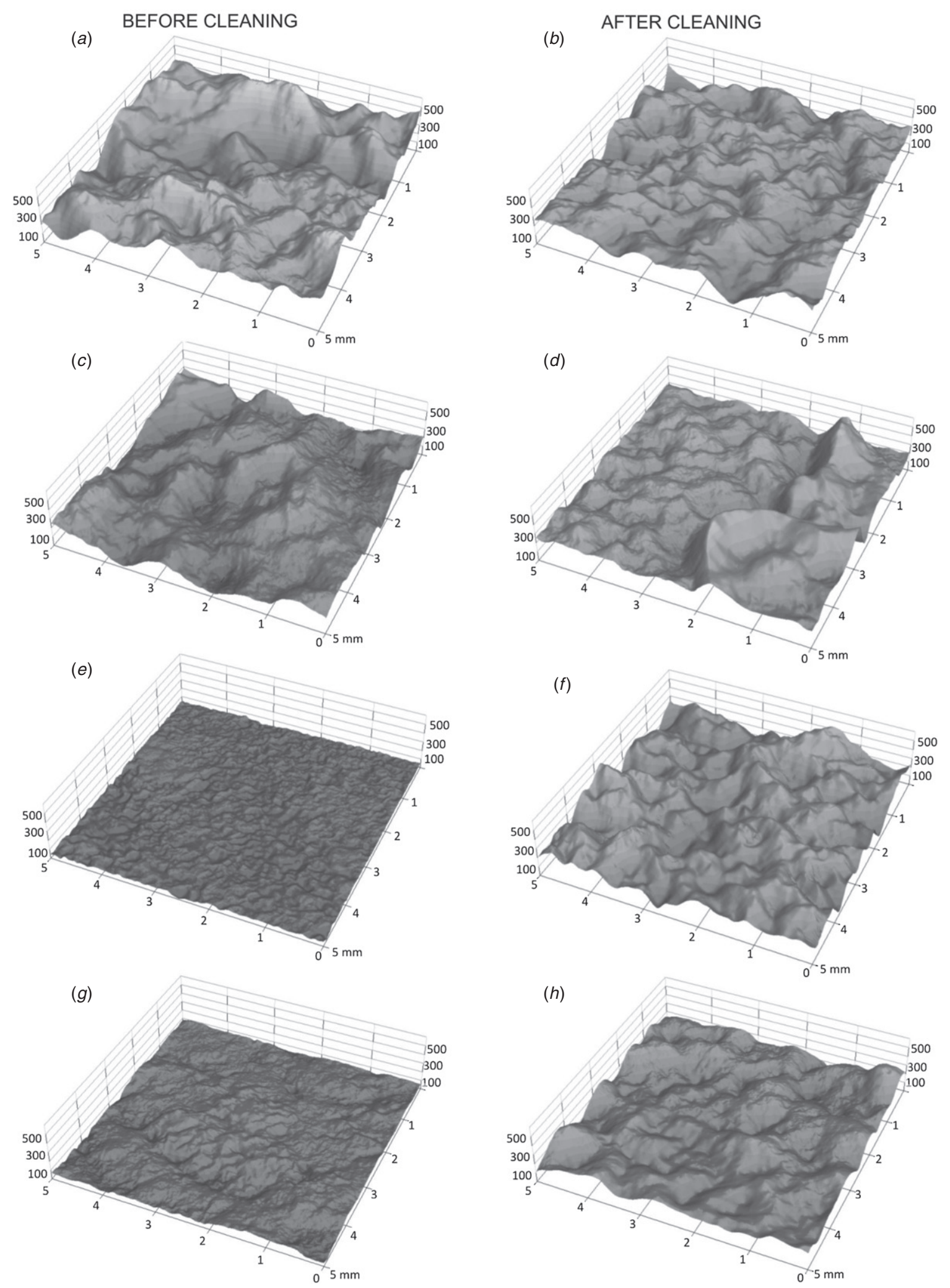

Figure 5. 3D roughness maps of stone samples before (left column) and after cleaning (right column): $(a),(b),(e),(f)$ white stone variety samples; $(c),(d),(g),(h)$ yellow stone variety samples; $(b),(d)$ cleaning operating conditions \#3; $(f)$ cleaning operating conditions \#5; (h) cleaning operating conditions \#1. 

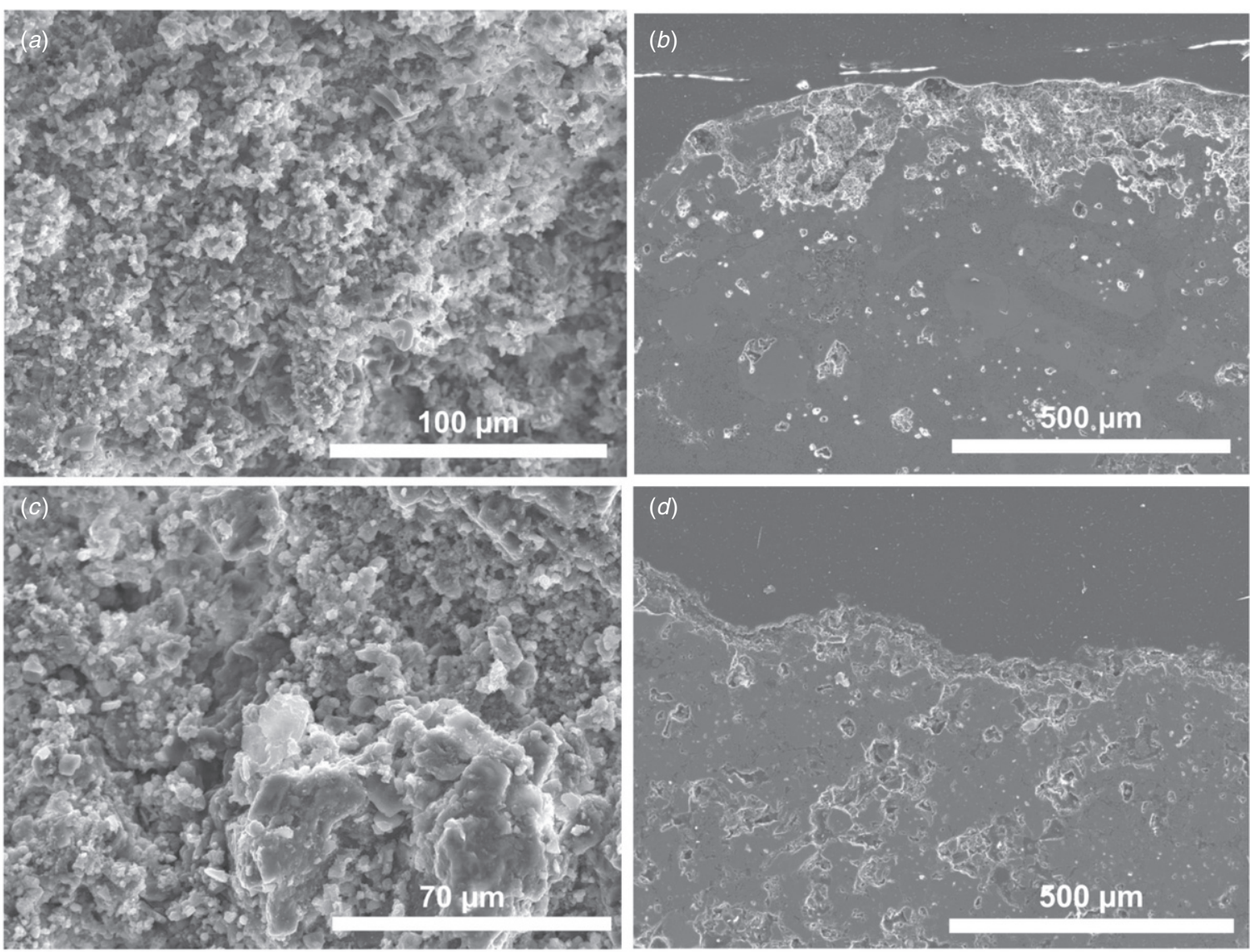

Figure 6. SEM images of cleaned stone samples. Plots $(a)$ and $(b)$ correspond to the white stone variety (W1 area) and $(c)$ and $(d)$ to the yellow stone variety (Y3 area). Plots $(a)$ and $(c)$ are images of the surface (fragments) and $(b)$ and $(d)$ are cross sections of polished thin sections with the stone surface on top of the images.

\section{Conclusions}

The cloister was built with two types of stone, usually intermingled, named in this paper as white and yellow varieties, different in their petrography, mineralogy and texture, as well as the deposits accumulated on them, responsible for the stone soiling and darkening, for which cleaning intervention for their removal was planned by the architect in charge of the project.

The results obtained in this study allowed assessing the best of the selected and tested methods for cleaning the stones of the cloister of the Cathedral of Segovia, Spain.

Attending the white stone variety, was the cleaning method \#1 (glass micro-spheres, 90/150 $\mu \mathrm{m},<1 \mathrm{~atm}$ ), with which the results were most effective. In the case of the yellow stone variety, best results from colour and roughness measurements were obtained using the cleaning method \#3 (aluminium oxide particles (150), $105 \mu \mathrm{m}$ in diameter, and $<1$ atm pressure).

Nevertheless, considering that only one of the operating conditions was planned to be used, as well as the fact that these two stone varieties are frequently intermingled in the cloister, cleaning method \#3 could be used for both of them, as this method was also effective and suitable for cleaning the white stone variety, according to the results mentioned above.

The methodology followed in this study combining roughness and colour measurements (highlighting that they are non-destructive and portable techniques), together with the microscopic observations of small samples, proved very useful and reliable in assessing the effect and efficiency of any cleaning method to be used in heritage buildings.

Finally, the results obtained do not rule out that other stone cleaning methods not tested nor assessed here, could be less aggressive or adequate for use in heritage building cleaning.

\section{Acknowledgments}

The authors gratefully acknowledge both programmes, i.e. CONSOLIDER (CSD2007-0058) and GEOMATERIALES (S2009/MAT-1629), and are thankful to the Complutense University of Madrid (UCM) Research Group ref. 921349.

\section{References}

Alvarez de Buergo M, Vazquez-Calvo C and Fort R 2011 The measurement of surface roughness to determine the suitability of different methods for stone cleaning Geophys. Res. Abstracts 13 EGU2011-6443 EGU General Assembly 2011

Benavente D, Martinez-Verdu F, Bernabeu A, Viqueira V, Fort F, García del Cura M A, Illueca C and Ordoñez S 2003 Influence of surface roughness on color changes in building stones Color Res. Appl. 28 343-51

Colombo C, Daffara C, Fontana R, Gambino M C, Mastroianni M, Pampaloni E, Realini M and Sansonetti A 2007 Evaluation by 
laser micro-profilometry of morphological changes induced on stone materials by laser cleaning LACONA VI: Lasers in the Conservation of Artworks (Vienna, Austria, 21-25 Sept. 2005) (Springer Proceedings in Physics vol 116) ed J Nimmrichter, W Kautek and M Schreiner (Berlin: Springer) pp 523-26

Della Volpe C, Penati A, Peruzzi R, Siboni S, Toniolo L and Colombo C 2000 The combined effect of roughness and heterogeneity on contact angles: the case of polymer coating for stone protection J. Adhes. Sci. Technol. 14/2 273-99(27)

Dunham R J 1962 Classification of carbonate rocks according to depositional texture Classification of Carbonate Rocks vol 1 ed W E Ham (American Association of Petroleum Geologists Memoir) pp 108-21

Folk R L 1962 Spectral subdivision of limestone types Classification of Carbonate Rocks vol 1 ed W E Ham (American Association of Petroleum Geologists Memoir) pp 62-84

Fort R, Mingarro F, López de Azcona M C and Rodríguez Blanco J 2000 Chromatic parameters as performance indicators for stone cleaning techniques Color Res. Appl. 25 442-6

Fort R, Vazquez-Calvo C, Chapa T, Martínez-Navarrete I and Belen M 2012 An analytical study of Iberian Iron Age stone sculptures and their surface marks Archaeometry doi:10.1111/j.1475-4754.2012.00686.x

Grissom C A, Charola A E and Wachowiak M J 2000 Measuring surface roughness on stone: back to basics Stud. Conserv. 45/2 73-84

Guidobaldi F and Mecchi A M 1993 Corrosion of ancient marble monuments by rain: evaluation of pre-industrial recession rates by laboratory simulations Atmos. Environ. B 27 339-51

Iglesias M, Gea B, Prada J L and Guasch N 2006 Low-pressure abrasive cleaning of historic building materials Heritage, Weathering and Conservation vol 2 ed R Fort, M Alvarez de
Buergo, M Gomez-Heras and C Vazquez-Calvo (Balkema, Leiden) pp 681-6

Illescas J F and Mosquera M J 2011 Surfactant-synthesized PDMS/silica nanomaterials improve robustness and stain resistance of carbonate stone J. Phys. Chem. C 115 14624-34

Jaynes S M and Cooke R U 1987 Stone weathering in Southeast England Atmos. Environ. 21 1601-22

Lopez-Arce P, Gomez-Villalba L S, Pinho L, Fernández-Valle M E, Álvarez de Buergoa M and Fort R 2010a Influence of porosity and relative humidity on consolidation of dolostone with calcium hydroxide nanoparticles: effectiveness assessment with non-destructive techniques Mater. Charact. 61 168-84

Lopez-Arce P, Varas-Muriel M J, Fernandez-Revuelta B, Alvarez de Buergo M, Fort R and Perez-Soba C 2010b Artificial weathering of Spanish granites subjected to salt crystallization tests: surface roughness quantification Catena 83 170-85

Manoudis P, Karapanagiotis I, Tsakalof A, Zuburtikudis I, Kolinkeová B and Panayiotou C 2009 Superhydrophobic films for the protection of outdoor cultural heritage assets Appl. Phys. A 97 351-60

Manoudis P, Papadopoulou S, Karapanagiotis I, Tsakalof A, Zuburtikudis I and Panayiotou C 2007 Polymer-silica nanoparticles composite films as protective coatings for stone-based monuments J. Phys.: Conf. Ser. 61 1361-5

Perez-Monserrat E M, Varas M J, Fort R and Alvarez de Buergo M 2011 Cleaning methods assessment for the limestone façades of the formerly Workers Hospital of Madrid, Spain Stud. Conserv. 56 297-312

Young M E, Andrew C A, MacDonald J, Thomson B W, Tonge K H, Urquhart D C M, Webster R G M and Wilson M J 1994 Stonecleaning in Scotland Alteración de granitos y rocas afines. Deterioro de monumentos históricos ed V Molina pp 173-9 